\title{
Lenalidomide Maintenance Regimen
}

National Cancer Institute

\section{Source}

National Cancer Institute. Lenalidomide Maintenance Regimen. NCI Thesaurus. Code C160075.

A chemotherapy regimen consisting of lenalidomide maintenance that may be used in the treatment of chronic lymphocytic leukemia (CLL), small lymphocytic lymphoma (SLL), and diffuse large B-cell lymphoma (DLBCL). 